\title{
Severe Early Life Stress Hampers Spatial Learning and Neurogenesis, but Improves Hippocampal Synaptic Plasticity and Emotional Learning under High-Stress Conditions in Adulthood
}

\author{
Charlotte A. Oomen, ${ }^{1}$ Heleen Soeters, ${ }^{1}$ Nathalie Audureau, ${ }^{1}$ Lisa Vermunt, ${ }^{1}$ Felisa N. van Hasselt, ${ }^{1}$ Erik M. M. Manders, ${ }^{2}$ \\ Marian Joëls, ${ }^{1,3}$ Paul J. Lucassen, ${ }^{1}$ and Harm Krugers ${ }^{1}$ \\ ${ }^{1}$ Center for Neuroscience and ${ }^{2}$ Center for Advanced Microscopy, University of Amsterdam, 1098 XH Amsterdam, The Netherlands, and ${ }^{3}$ Rudolf Magnus \\ Institute for Neurosciences, University Medical Center Utrecht, 3584 CG Utrecht, The Netherlands
}

\begin{abstract}
Early life stress increases the risk for developing stress-related pathologies later in life. Recent studies in rats suggest that mild early life stress, rather than being overall unfavorable, may program the hippocampus such that it is optimally adapted to a stressful context later in life. Here, we tested whether this principle of "adaptive programming" also holds under severely adverse early life conditions, i.e., $24 \mathrm{~h}$ of maternal deprivation (MD), a model for maternal neglect. In young adult male rats subjected to MD on postnatal day 3 , we observed reduced levels of adult hippocampal neurogenesis as measured by cell proliferation, cell survival, and neuronal differentiation. Also, mature dentate granule cells showed a change in their dendritic morphology that was most noticeable in the proximal part of the dendritic tree. Lasting structural changes due to MD were paralleled by impaired water maze acquisition but did not affect long-term potentiation in the dentate gyrus. Importantly, in the presence of high levels of the stress hormone corticosterone, even long-term potentiation in the dentate gyrus of MD animals was facilitated. In addition to this, contextual learning in a high-stress environment was enhanced in MD rats. These morphological, electrophysiological, and behavioral observations show that even a severely adverse early life environment does not evolve into overall impaired hippocampal functionality later in life. Rather, adversity early in life can prepare the organism to perform optimally under conditions associated with high corticosteroid levels in adulthood.
\end{abstract}

\section{Introduction}

Epidemiological studies in humans have shown that adverse early life events can increase the risk for the development of psychopathology in adulthood (Heim and Nemeroff, 2001; McEwen, 2003). In rodents, effects of early life stress can be studied in a controlled manner by long-term removal of the dam, i.e., maternal separation or maternal deprivation (MD) during the first 2 weeks of life, which increases hypothalamopituitary-adrenal (HPA) axis activity in the offspring (Levine et al., 1991; Schmidt et al., 2004; Oomen et al., 2009). This rise in corticosterone (CORT) during the so-called stress hyporesponsive period is thought to exert long term programming effects on HPA axis parameters (Plotsky and Meaney, 1993; Penke et al., 2001; Workel et al., 2001; Lehmann et al., 2002).

\footnotetext{
Received Jan. 15, 2010; revised March 23, 2010; accepted March 30, 2010.

P.J.L. was supported by the Nederlandse Hersenstichting, the European Union (Neurodegeneration in Alzheimer's Disease), ISA0, and the Volkswagen Stiftung Germany. We thank Joop van Heerikhuize (Netherlands Institute for Neuroscience, Amsterdam, The Netherlands) for assistance with the Neurodraw software; Els Velzing (Swammerdam Institute for Life Sciences, University of Amsterdam, Amsterdam, The Netherlands) for technical assistance, and Maaike van der Mark (Leiden/Amsterdam Center for Drug Research, Leiden University, Leiden, The Netherlands) for the analysis of plasma corticosterone levels.

Correspondence should be addressed to Charlotte Oomen, Swammerdam Institute for Life Sciences, Center for Neuroscience, University of Amsterdam, Science Park 904, 1098 XH Amsterdam, The Netherlands. E-mail: c.a.oomen@uva.nl.

D0I:10.1523/JNEUROSCI.0247-10.2010

Copyright $\odot 2010$ the authors $\quad 0270-6474 / 10 / 306635-11 \$ 15.00 / 0$
}

When stress occurs during the first two postnatal weeks in rodents, it coincides with the development of the dentate gyrus (DG) of the hippocampus (Altman and Bayer, 1990a, 1990b), a brain region involved in learning and memory and sensitive to glucocorticoid exposure (McEwen and Magarinos, 2001; de Kloet et al., 2005). Emphasizing its persistent nature, MD in rodents was found to affect hippocampal structure in adulthood, resulting in lower hippocampal neuron and glia numbers (Leventopoulos et al., 2007; Fabricius et al., 2008) and reduced mossy fiber density (Huot et al., 2002). With respect to adult hippocampal neurogenesis, repeated maternal separation was shown to reduce only cell proliferation (Mirescu et al., 2004; Aisa et al., 2009) but not newborn cell survival in rats (Mirescu et al., 2004; Greisen et al., 2005; Petersen et al., 2008). These studies confirm the potentially unfavorable effects of early life stress.

Very recent studies, however, suggest that rather than being overall unfavorable, early life stress may program the hippocampus such that it optimally responds to stressful contexts encountered later in life (Champagne et al., 2008, 2009; Lyons et al., 2009). For example, the adult male offspring of low- versus highcaring mothers showed reduced synaptic plasticity when animals were studied under nonstress conditions, but when studied under conditions that mimic stress, low- versus high-care offspring exhibited enhanced synaptic plasticity (Champagne et al., 2008; 
Bagot et al., 2009). In agreement, offspring from low-caring mothers performed poorly in relatively low-stress learning conditions (Liu et al., 2000), but outperformed the high-care offspring in stressful learning tasks (Champagne et al., 2008; Bagot et al., 2009).

As differences in maternal care represent relatively small natural variations in the early life environment, we here asked whether the principle of "adaptive programming" also holds under severe early life stress conditions of prolonged ( $24 \mathrm{~h}$ ) absence of the mother at postnatal day 3 (PND3). Therefore, we studied the consequences of early MD on different phases of adult hippocampal neurogenesis and granule cell morphology in males. In addition, we determined the functional consequences of maternal deprivation by investigating spatial and emotional learning and memory as well as synaptic plasticity in the dentate gyrus after MD, both under low-to-moderate stress conditions and in a high-stress emotional context.

\section{Materials and Methods}

Animals and breeding procedure. All animal procedures presented in this article were approved by the animal ethics committee of the University of Amsterdam (Amsterdam, The Netherland). To minimize variation and avoid stress in the perinatal environment, all animals were bred in house. Wistar rats were purchased from Harlan CBP, kept under standard housing conditions (12/12 h dark/light phase, lights on at 8:00 A.M., humidity $55 \pm 15 \%$, temperature $20-22^{\circ} \mathrm{C}$ ), and habituated to the animal facilities for $10 \mathrm{~d}$. For breeding, one male rat was put together with two females for a period of 1 week. After mating, females were pair housed until the beginning of the third gestational week. Then, females were individually housed with extra bedding material and monitored for birth each morning at 9:00 A.M. If a litter was found, the previous day was designated PND0, the day of birth. Dams with litters were left undisturbed until PND3 and then randomly assigned to one of the two experimental groups [MD or control (CON) procedure], making sure that litters from the same father were not in the same experimental group.

Maternal deprivation procedure. On the morning of PND3 (9:00 A.M.), litters were separated from their mother as a whole, handled shortly, culled to four males and four females, and placed back into their home cage. The cage was placed on a heating pad in another room to avoid disturbance by vocalization in the breeding room. The dam was housed in a novel cage and returned to the breeding room. Litters were kept at a constant temperature of $32^{\circ} \mathrm{C}$ during the $24 \mathrm{~h}$ deprivation period. Litters were, with the exception of two litters of six pups, larger than or equal to eight pups, with an average of $11 \pm 2$ pups. Due to large litter size, culling to four males and four females was usually possible. This study repeated the exact same experimental procedure as used in our previous study (Oomen et al., 2009). No pups were lost during the MD procedure. At 9:00 A.M. on PND4, cages were cleaned by replacing some of the sawdust, after which the dam was returned to the nest. Litters from the CON group were culled and partially cleaned at the moment of disturbance on PND3 (11:00 A.M.). Cages were put back into the breeding room and left undisturbed until weaning, with the exception of PND14, when some of the sawdust was replaced. On PND21, pups were weaned and housed in groups of four same-sex littermates for experiments I, II, III, and IV or in pairs for experiment $\mathrm{V}$.

Experiment I: baseline and stress-induced corticosterone levels. To investigate the effect of early life stress on baseline corticosterone levels, 8- to 13 -week-old CON $(n=30)$ and MD $(n=23)$ rats were killed by rapid decapitation between 9:00 and 10:00 A.M., trunk blood was collected in EDTA-covered tubes, centrifuged (5000 rpm for $20 \mathrm{~min}$ ), and blood plasma was stored at $-20^{\circ} \mathrm{C}$ until further processing. Stress-induced corticosterone levels were measured in a different cohort of CON $(n=8)$ and $\operatorname{MD}(n=9)$ rats of 14-16 weeks of age. In the morning (between 9:00 and 10:00 A.M.), rats were brought to a novel room where a baseline blood sample was collected by tail bleeding from a small incision made halfway down the length of the tail (Fluttert et al., 2000). Blood was collected in an EDTA-covered capillary tube. Thirty minutes later, rats were brought to the same room to collect a second sample by means of tail bleeding, which was considered the stress-induced blood sample. Blood was processed and stored as described above. Two weeks later, corticosterone levels were determined in the same animals during recovery from a swim stress. For this reason, rats were placed into a water maze $\left(22^{\circ} \mathrm{C}, 150 \mathrm{~cm}\right.$ in diameter, no platform present) for 2 min between 9:00 and 10:00 A.M. After this, rats were taken out of the water and placed back into their home cage. One hour after swim stress, rats were decapitated and trunk blood was collected and processed as described above. Plasma corticosterone concentrations from all three experiments were measured in duplicate using a commercially available radio immunoassay kit (MP Biochemicals).

Experiment II: adult neurogenesis and dentate gyrus architecture. To determine lasting effects of early MD on different phases of adult neurogenesis, eight CON and eight MD males (from four CON and four MD litters) were injected with bromodeoxyuridine (BrdU; $200 \mathrm{mg} / \mathrm{kg}$, intraperitoneally; Sigma-Aldrich) on PND51 and killed $18 \mathrm{~d}$ later. On that day, animals were anesthetized in the morning by an injection of pentobarbital sodium salt (Nembutal; $1 \mathrm{mg} / \mathrm{kg}$ bodyweight; A.U.V. Cuijk) and perfused transcardially with saline followed by $4 \%$ paraformaldehyde in phosphate buffer (PB; $0.1 \mathrm{M}, \mathrm{pH}$ 7.4). To prevent pressure artifacts, brains were postfixed overnight in the skull at $4^{\circ} \mathrm{C}$, after which they were carefully removed, washed, and cryoprotected by $20 \%$ sucrose in PBS. Frozen sections ( $30 \mu \mathrm{m}$ thick) were cut using a sliding microtome and collected in PB with azide.

Different stages of neurogenesis were studied as described previously (Mayer et al., 2006; Oomen et al., 2007). Immunohistochemistry for $\operatorname{BrdU}$ (1:2000; monoclonal murine anti-BrdU; Roche) was used to assess cell proliferation/newborn cell survival. The marker Ki-67, a cell cyclerelated protein identifying all cells actively engaged in cell cycle (1:2000; polyclonal rabbit $\alpha$-Ki-67; Novocastra), was used to assess cell proliferation. In addition, the number of young, differentiating neurons was identified with an antibody against the microtubule-associated protein doublecortin (DCX; 1:800; polyclonal goat anti-DCX; Santa Cruz Biotechnology). Amplification was performed with a biotinylated secondary antibody [sheep anti-mouse (1:200; GE Healthcare), goat anti-rabbit (1:200; Vector Laboratories), or donkey anti-goat (1:500; Jackson ImmunoResearch Laboratories)] and avidin-biotin complex (1:1000; Elite Vectastain $\mathrm{ABC}$ kit, Brunschwig Chemie) in combination with tyramide (1:500; $0.01 \% \mathrm{H}_{2} \mathrm{O}_{2}$; kindly provided by Dr. I. Huitinga, Netherlands Institute for Neuroscience, Amsterdam, The Netherlands). Subsequent chromogen development was done with diaminobenzidine (20 mg per $100 \mathrm{ml}$ of Tris buffer, $0.01 \% \mathrm{H}_{2} \mathrm{O}_{2}$ ).

All stereological quantification procedures described below were performed in every 10th coronal section along the entire rostrocaudal axis, in a total of 9 sections per animal. Total numbers of DG granule neurons and DCX-positive cells were quantified by systematic random sampling performed with the Stereo Investigator system (MicroBrightField). Stereo Investigator optical fractionator settings for the quantification of DCX were $140 \times 80$ grid size and $50 \times 50$ counting frame, which resulted in 300-500 markers per animal. StereoInvestigator settings for total granule cell count were $150 \times 150$ grid size and $15 \times 15$ counting frame, which resulted in 300-500 markers per animal.

We further distinguished morphologically different subtypes of the DCX-immunopositive cells, reflecting different stages of neuronal differentiation (Plumpe et al., 2006); the most mature DCX-positive cells were characterized by a primary dendrite that was orientated perpendicular to the subgranular zone and protruding into the molecular layer (categories E and F). DCX-positive cells without dendrites (category A), horizontally orientated dendrites, or dendrites growing into the granule cell layer but not into the molecular layer (categories B-D) are considered less mature and can still undergo cell division (Kronenberg et al., 2003; Plumpe et al., 2006; Walker et al., 2007).

Because of the relatively sparse occurrence and clustering of Ki-67positive and BrdU-positive cells, these cells were counted manually by means of a modified stereological procedure using a Zeiss microscope ( $200 \times$ magnification) and multiplied by 10 to estimate the total number of Ki-67-positive and BrdU-positive cells in the DG (van Praag et al., 1999; Oomen et al., 2007). Dentate gyrus granule cell layer and molecular 
layer surface area and volume measurements were performed according to Cavalieri's principle using the Stereo Investigator system (MicroBrightField).

Experiment III: granule cell morphology. Effects of maternal deprivation on granule cell morphology were determined by analyzing the dendritic tree of Golgi-stained neurons using three-dimensional (3D) reconstruction software. For this purpose, 8- to 13-week-old CON $(n=7)$ and MD $(n=7)$ animals were decapitated in the morning between 9:00 and 10:00 A.M. and trunk blood was collected in EDTA-covered tubes (experiment I). Immediately after decapitation, brains were rapidly removed and cut into two hemispheres. One hemisphere was used for Golgi-Cox impregnation and the other for electrophysiological recordings (experiment IV).

For Golgi-Cox impregnation, a similar procedure was used as described previously (Boekhoorn et al., 2006; Champagne et al., 2008; Bagot et al., 2009). Immediately after decapitation, brains were incubated in a Golgi-Cox solution $\left(5 \% \mathrm{~K}_{2} \mathrm{CrO}_{4}, 5 \% \mathrm{HgCl}\right.$, and $\left.5 \% \mathrm{~K}_{2} \mathrm{Cr}_{2} \mathrm{O}_{7}\right)$ for $28 \mathrm{~d}$, after which they were imbedded in celloidine and cut into $200-\mu \mathrm{m}$ thick sections. From each animal, $Z$-stacks (step size $1 \mu \mathrm{m}$ ) from 5-7 dentate granule cells were generated using a confocal microscope (LSM510, Zeiss) in bright-field mode (20× objective) and reconstructed in ImagePro in combination with the NeuroDraw toolbox (kindly provided by G. Ramakers, J. van Heerikhuize, and C. Pool, Netherlands Institute for Neuroscience). Criteria for inclusion were as follows: (1) only neurons from the suprapyramidal blade of the rostral dentate gyrus, -2.5 to $-4.0 \mathrm{~mm}$ from bregma (Paxinos and Watson, 1986) were selected; (2) cells had to be evenly filled, without any severed dendrites exiting the section; (3) only cells from the middle third part of the granular cell layer were chosen to avoid relatively newborn granule cells residing in the inner part of the cell layer or cells formed early in ontogeny (embryonic days 21-22) that reside in the outer third part of the cell layer (Altman and Bayer, 1990a,b). Total dendritic length, number of branch points, and the number of primary dendrites were analyzed for every neuron. In addition, spine density was determined in two segments of dendrites at a distance of $90-110 \mu \mathrm{m}$ (proximal) and 190-210 $\mu \mathrm{m}$ (distal) from the soma. Also, for each reconstructed neuron, a 3D Sholl analysis was performed using the free software package NeuronStudio (Wearne et al., 2005). Data from 5-7 neurons were averaged per animal and used in further statistical analysis.

Experiment IV: electrophysiological properties of the dentate gyrus. To determine effects of maternal deprivation on electrophysiological properties of the DG network, 42 8- to 13-week-old male rats were decapitated in the morning between 9:00 and 10:00 A.M. If possible, two measurements were performed in each animal: one under vehicle (VEH) conditions and one under corticosterone conditions. In total, this resulted in 67 long-term potentiation (LTP) recordings in the presence and absence of bicuculline. First, we studied LTP in the absence of the GABAergic antagonist bicuculline in 12 control and $9 \mathrm{MD}$ animals. Because this did not induce significant LTP, further experiments were performed in the presence of bicuculline in $11 \mathrm{CON}$ and $10 \mathrm{MD}$ animals.

For these experiments, stress from individual housing was avoided by decapitating the last two animals from the same cage simultaneously. Immediately after decapitation, the brain was rapidly removed and cut into two hemispheres. The left hemisphere was collected for Golgi-Cox impregnation (experiment III) and the right hemisphere was collected for electrophysiological recordings in ice-cold artificial CSF (aCSF) containing $120 \mathrm{~mm} \mathrm{NaCl}, 3.5 \mathrm{~mm} \mathrm{KCl}, 1.3 \mathrm{~mm} \mathrm{MgSO}{ }_{4} .7 \mathrm{H}_{2} \mathrm{O}, 1.25 \mathrm{~mm}$ $\mathrm{NaH}_{2} \mathrm{PO}_{4}, 2.5 \mathrm{~mm} \mathrm{CaCl}_{2} \cdot 2 \mathrm{H}_{2} \mathrm{O}, 10 \mathrm{~mm}$ glucose, and $25 \mathrm{~mm} \mathrm{NaHCO}_{3}$ and oxygenated with $95 \% \mathrm{O}_{2}$ and $5 \% \mathrm{CO}_{2}$. Coronal slices ( $\left.400 \mu \mathrm{m}\right)$ were cut using a microtome (Leica VT1000S) at $5^{\circ} \mathrm{C}$ and then kept in oxygenated aCSF at room temperature for at least $2 \mathrm{~h}$ before recording. Sections containing the rostral part $(-2.5$ to $-4.0 \mathrm{~mm}$ from bregma) (Paxinos and Watson, 1986) of the hippocampal dentate gyrus were placed in a recording chamber maintained at $30-32^{\circ} \mathrm{C}$ with a constant flow of oxygenated aCSF. Field EPSPs (fEPSPs) were recorded as described previously (Pu et al., 2007; Bagot et al., 2009) in the absence or presence of the GABAergic antagonist bicuculline methiodide (10 $\mu$ m; Tebu-bio). fEPSPs were evoked using a stainless steel bipolar stimulation electrode (60 $\mu \mathrm{m}$ diameter, insulated except for the tip) positioned in the medial per- forant pathway and recorded through a glass electrode (2-5 M $\Omega$ impedance, filled with aCSF) positioned in the middle third of the molecular layer of the upper blade. A stimulus-response curve was generated by gradually increasing the stimulus intensity to define a level that generated the half-maximal response that was used for the remainder of the experiment. Once the input-output curve for each recording was established, baseline synaptic transmission was monitored $(0.017 \mathrm{~Hz})$ during $20 \mathrm{~min}$. When recordings were stable, theta burst stimulation (four pulses of 100 $\mathrm{Hz}$ followed by a $200 \mathrm{~ms}$ interval, followed by another four pulses) was applied. This sequence was repeated $5 \times$ with a $30 \mathrm{~s}$ interval. After theta burst stimulation, the degree of potentiation was determined by recording the fEPSP every minute during $1 \mathrm{~h}(0.017 \mathrm{~Hz})$. The magnitude of the fEPSP was assessed by analyzing the slope of the signal. To determine whether the presence of the stress hormone corticosterone during stimulation modulates the degree of LTP, corticosterone (100 nM, dissolved in $0.01 \%$ ethanol; Sigma-Aldrich) or vehicle $(0.01 \%$ ethanol) was added to the aCSF during the second half of baseline recordings $(t=-10$ to 0 min), coterminating with theta burst stimulation (Bagot et al., 2009). This concentration of corticosterone was shown before to occupy both mineralocorticoid receptor and glucocorticoid receptor and is therefore comparable and relevant to mimic in vivo stressful situations (Karst et al., 2000; Champagne et al., 2008).

Experiment V: behavior. One cohort of animals (10 CON and $10 \mathrm{MD}$ rats) was used for three behavioral tasks described in the following section. Animals were housed in pairs. During testing, rats from the same home cage were tested on different days to avoid effects of acute stress. Before and in between tasks, rats were handled every other day, starting 2 weeks before the start of the first experiment. The order of testing was as described below, and the time in between tasks was at least 1 week. All behavioral tests were performed between 8:00 and 12:00 A.M.

To study potential changes in basal exploration and anxiety levels after maternal deprivation, $\mathrm{CON}(n=10)$ and $\mathrm{MD}(n=10)$ rats were tested in an elevated plus maze at the age of 11 weeks. For this, each rat was transferred from its home cage to the experimental setup in the adjacent room. In this testing room, at a light intensity of 60 lux, the animals were put on the center of an elevated plus maze $(100 \mathrm{~cm}$. from the ground) facing one of the two open arms. The plus maze was made of black plastic and shaped like a cross with two opposite open arms $(10 \times 40 \mathrm{~cm})$ and two opposite closed arms $(10 \times 40 \mathrm{~cm}, 25 \mathrm{~cm}$ high walls $)$ connected to an open center. Animals were placed in the center and allowed to freely explore the open and closed arms for $5 \mathrm{~min}$. Exploration patterns were recorded by a video camera coupled to a computer and processed by EthoVision (Noldus). Total time, frequency and latency to first appearance in all compartments of the maze were analyzed to determine the exploration pattern.

To determine spatial learning ability of MD rats, animals were trained in a Morris water maze (Morris, 1984$)$. CON $(n=10)$ and MD $(n=10)$ animals ( 13 weeks old) were trained in $2 \mathrm{~d}$, during which they received 4 trials per day with an intertrial interval of $15 \mathrm{~min}$. The water maze (150 $\mathrm{cm}$ in diameter) was situated in a room adjacent to where animals were housed and filled with opaque water $\left(22^{\circ} \mathrm{C}\right.$, with added nontoxic paint). In one quadrant (northwest), a transparent platform ( $12 \mathrm{~cm}$ in diameter) was hidden $0.5 \mathrm{~cm}$ under the water surface. During training, trials were started in one of the three quadrants without platform (i.e., northeast, southwest, or southeast quadrant), and the starting position alternated between trials, rats, and days. At the start of each trial rats were placed in the water facing the wall of the pool. Animals were allowed to swim in the maze until they reached the platform or until a maximum time of $2 \mathrm{~min}$ was reached. When rats were unable to find the platform, they were guided there manually. Animals were left on the platform for an additional $20 \mathrm{~s}$. Trials were recorded and analyzed for latency, swim distance, and time in the platform quadrant (EthoVision; Noldus).

To assess hippocampus and amygdala-dependent emotional memory, rats were subjected to contextual and cued fear conditioning (Phillips and LeDoux, 1992; Zhou et al., 2009). During fear conditioning, 15week-old rats $(\mathrm{CON}=10 ; \mathrm{MD}=10)$ learned to associate a fearful stimulus (footshock) with a context (conditioning box) and a cue (tone). The strength of fear-associated memory was determined by measuring the amount of freezing behavior. Scoring was done manually, every $2 \mathrm{~s}$, 
by two observers blinded to the experimental group. Rats were habituated to the experimental room starting $2 \mathrm{~d}$ before conditioning. Animals were trained by placing them in the fear-conditioning box $(30 \times 26 \times 24$ $\mathrm{cm}$, walls made of black and transparent plastic with metal grid floor), which they were allowed to explore freely for $3 \mathrm{~min}$. After that, a $30 \mathrm{~s}$ tone was played $(100 \mathrm{~dB}, 2.8 \mathrm{kHz})$ that coterminated with a footshock $(2 \mathrm{~s}, 0.4$ $\mathrm{mA})$. On the second day at the same time, animals were put into the conditioning box for 3 min under identical circumstances (i.e., the same cleaning solvent, lighting conditions, gloves, and lab coats). Contextual memory was evaluated by scoring freezing behavior. Two hours later, cued memory was tested by placing rats in a different box, with a solid white floor and light-colored walls under changed circumstances (i.e., different cleaning solvent, lighting conditions, gloves, and lab coat). Again, rats were allowed to explore the box freely for $3 \mathrm{~min}$, after which the tone was presented for $30 \mathrm{~s}$. Rats remained in the box for an additional $60 \mathrm{~s}$ to determine the behavioral response to the cue.

Statistical analysis. Statistical analysis was performed using SPSS16.0. All data are presented as average \pm SEM. Differences between CON and $\mathrm{MD}$ animals concerning body weight, corticosterone levels, levels of neurogenesis (all expressed per hemisphere), morphological parameters, and water maze probe trial were tested for significance using a two-tailed Student's $t$ test with a probability level of $5 \%$ after determining equality of variances using Levene's test (all data $p>0.05$ ).

Differences in Sholl plots, acquisition of the water maze, and contextdependent and cue-dependent freezing were tested with a single-factor repeated-measures ANOVA using early life treatment as a betweensubjects factor. The within-subjects factors used were as follows: interval from the soma (Sholl plot), trial (water maze), consecutive time interval (contextual fear conditioning), and before-tone versus after-tone interval (cued fear conditioning), respectively.

Effects of corticosterone treatment on baseline synaptic transmission were tested by comparing the average slope of the fEPSP of the first baseline ( -20 to $-10 \mathrm{~min}$ ) with that of the second baseline ( -10 to 0 min) using a three factor repeated-measures ANOVA (between-subjects factors: early life treatment and drug-treatment; within-subjects factor: baseline). To determine the effects of early life stress and application of the stress hormone corticosterone on the degree of LTP, a three-factor repeated-measures ANOVA was performed using early life treatment and corticosterone treatment as between-subject factors and pre-theta burst stimulation or post-theta burst stimulation as the within-subject factor. We compared the second baseline ( -10 to $0 \mathrm{~min}$ ) with early LTP; (0-30 min after theta burst stimulation) and total LTP (0-60 min after theta burst stimulation). When significant, a post hoc LSD test was performed to compare treatment groups.

\section{Results}

\section{Experiment I: body weight and stress responsiveness}

On PND51, MD animals had significantly ( $p=0.01$, both groups $n=8)$ lower bodyweights $(263 \pm 6 \mathrm{~g})$ compared with CON animals (291 $\pm 8 \mathrm{~g}$ ). As reported previously (Oomen et al., 2009), this difference in body weight after MD in adult animals was already present directly after deprivation, i.e., at PND4, and still discernable at PND21, which supports the idea that this effect is early in onset.

Baseline corticosterone levels were taken from animals decapitated in the morning between 9:00 and 10:00 A.M. These basal levels were not significantly affected by maternal deprivation $[\mathrm{CON}(n=30), 8.24 \pm 1.38 \mathrm{ng} / \mathrm{ml}$; MD $(n=23), 13.07 \pm 2.94$ $\mathrm{ng} / \mathrm{ml} ; p=0.12]$. In addition, $30 \mathrm{~min}$ after novelty stress, corticosterone levels were comparable between CON $(187 \pm 48 \mathrm{ng} /$ $\mathrm{ml})$ and $\mathrm{MD}(154 \pm 88 \mathrm{ng} / \mathrm{ml})$ animals $(p>0.1)$. One hour after swimming in a water maze, both CON $(427 \pm 84 \mathrm{ng} / \mathrm{ml})$ and MD $(281 \pm 46 \mathrm{ng} / \mathrm{ml})$ rats showed elevated corticosterone levels, with a trend toward a lower plasma corticosterone levels in MD animals $(p=0.1)$ (both groups $n=9$ ).
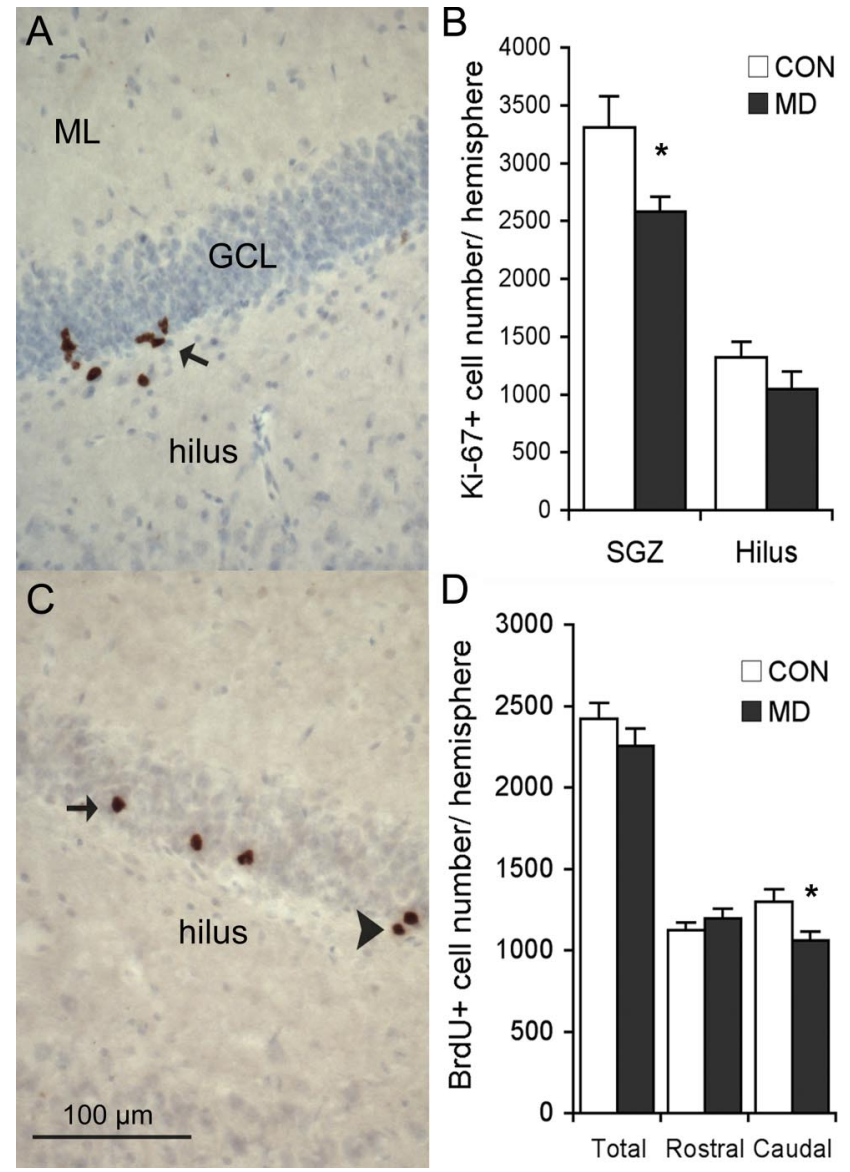

Figure 1. Effects of MD on hippocampal cell proliferation (Ki-67) and survival (BrdU). A, Photomicrograph of clustered Ki-67 labeled cells (arrow) in the subgranular zone of the dentate gyrus of 10-week-old rats. GCL, Granule cell layer; ML, molecular layer. $\boldsymbol{B}$, Total numbers of $\mathrm{Ki}-67$-positive cells in the subgranular zone (SGZ) and hilus per hemisphere $(n=8)$. MD treatment significantly reduced the number of Ki-67-positive cells in the subgranular zone $\left({ }^{*} p=\right.$ 0.03 ), but not the hilus $(p=0.2)$. C, Photomicrograph of BrdU labeled cells in the subgranular zone (arrowhead) and GCL (arrow). D, Total BrdU-positive cell numbers $(n=8)$ in the subgranular zone and granule cell layer per hemisphere were not affected by maternal deprivation ( $p=0.34$ ), but in the caudal part of the DG the number of BrdU-positive cells was significantly reduced $\left({ }^{*} p=0.03\right)$.

\section{Experiment II: adult neurogenesis is reduced by maternal deprivation}

Quantification of Ki-67-positive cells (Fig. 1A) revealed a significantly lower level of cell proliferation in the hippocampus of 10 -week-old MD rats when compared with control rats $(p=$ 0.03 , both groups $n=8$ ) (Fig. $1 B$ ). This effect was evenly distributed along the rostrocaudal axis (data not shown) and was specific for the subgranular zone and not present in the hilus $(p=0.2)$.

Overall cell proliferation/survival, as measured by the total number of BrdU-positive cells in the subgranular zone and granular cell layer (Fig. $1 C$ ), was not affected by MD $(p=0.34)$ (Fig. $1 D)$. However, when examined along the rostrocaudal axis, a significant decrease was found in the caudal part (last four sections -4.5 to $-6.7 \mathrm{~mm}$ from bregma) of the DG $(p=0.03)$ (Fig. 1D).

The total number of immature neurons was determined by DCX-positive cell numbers (Fig. 2A). Absolute DCX-positive cell numbers per hemisphere did not differ between CON and MD $(p=0.16)$ (Fig. $2 B$ ). Interestingly, we also observed here an effect along the rostrocaudal axis. MD males displayed lower ab- 

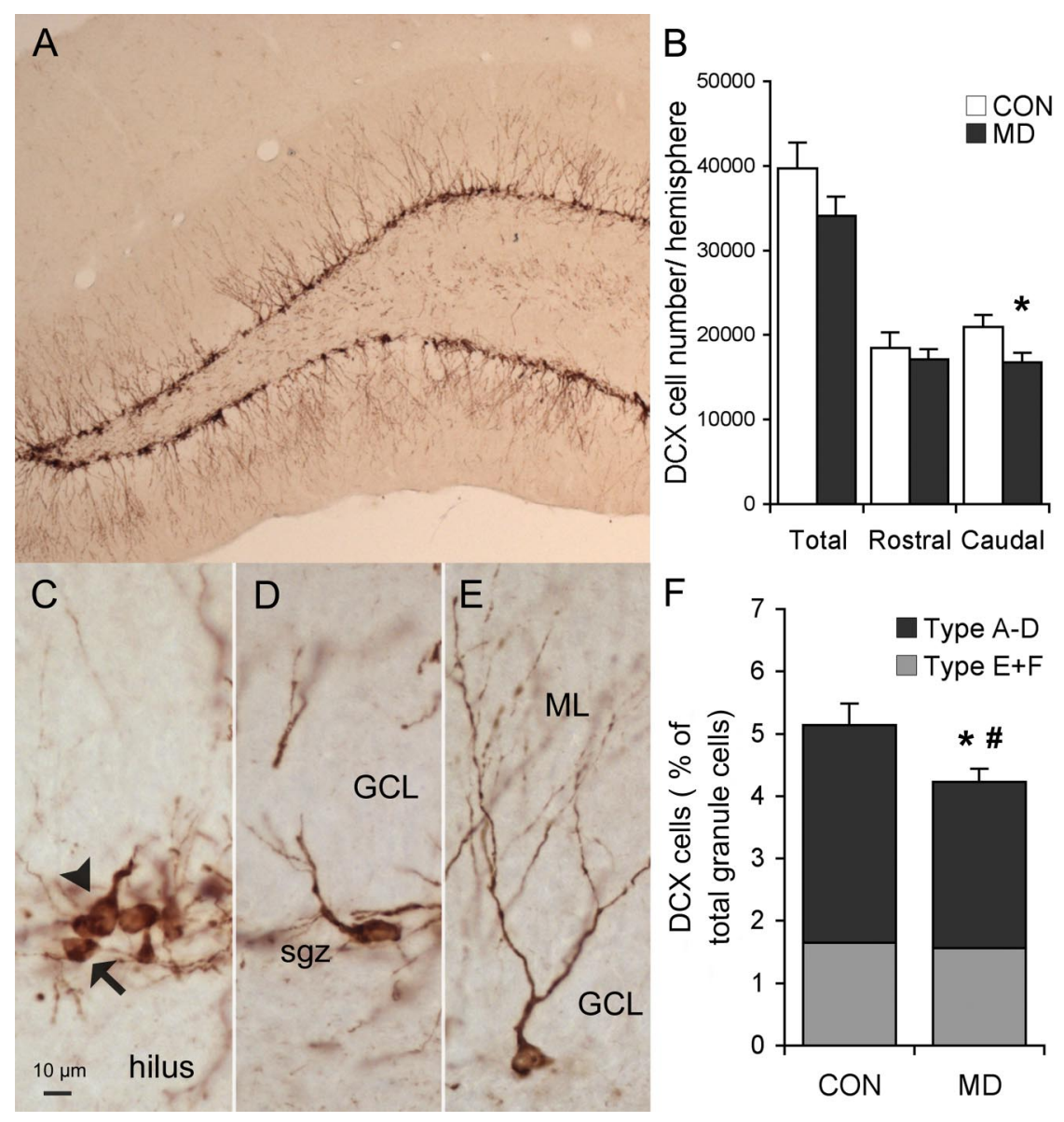

Figure 2. Effects of $M D$ on neuronal differentiation (doublecortin immunohistochemistry). $A$, Photomicrograph of the dentate gyrus of 10-week-old male rats, showing examples of DCX expression along the subgranular zone. $\boldsymbol{B}$, Total numbers of DCX-positive cells in the subgranular zone per hemisphere were not different between the groups $(n=8)$; however, MD treatment caused a significantly lower number of $D C X$-positive cells in the caudal part of the dentate gyrus $\left({ }^{*} p=0.04\right)$. $C$, Examples of relatively immature DCX-positive cells (arrow, category A; arrowhead, category B/C). D, An example of an intermediate DCX phenotype with outgrowing dendrites (category C). GCL, Granule cell layer; sgz, subgranular zone. $\boldsymbol{E}$, Example representing a mature DCX phenotype (category F). ML, Molecular layer. $\boldsymbol{F}$, The percentage of DCX-positive cells as a percentage of total granule cells was decreased in MD animals ( ${ }^{*} p=0.04$ ) because of a decline in the more immature DCX-positive cells (categories $A-D$ ); ${ }^{\#} p=0.01$. Mature DCX cell types were unaffected (classification according to Plumpe et al., 2006).

Table 1. Effects of MD on granule cell morphology ${ }^{a}$

\begin{tabular}{lcc}
\hline Morphological parameter & CON & MD \\
\hline Dendritic length $(\mu \mathrm{m})$ & $1602 \pm 115$ & $1608 \pm 78$ \\
Number of branch points & $8.1 \pm 0.9$ & $8.5 \pm 0.5$ \\
Number of primary dendrites & $2.96 \pm 0.1$ & $2.06 \pm 0.2^{*}$ \\
Maximum length of primary dendrites $(\mu \mathrm{m})$ & $253 \pm 11$ & $286 \pm 7^{*}$ \\
Spine density (number of spines $/ \mu \mathrm{m})$ & $0.5 \pm 0.06$ & $0.7 \pm 0.06^{\#}$
\end{tabular}

${ }^{a}$ Morphological features of granule cells in CON $(n=7)$ and MD $(n=7)$ animals are summarized. MD treatment resulted in a change in dendritic arrangement, most notably in the number and the maximum length of primary dendrites ( $\left.{ }^{*} p<0.05\right)$. In addition, a trend toward an increase in spine density was observed $\left({ }^{*} p<0.1\right)$.

solute DCX-positive cell numbers compared with control animals between -4.5 and $-6.7 \mathrm{~mm}$ from bregma $(p=0.04)$ (Fig. $2 B$ ). If the total (along the entire rostro-to-caudal axis) DCXpositive cell number is expressed as a percentage of total granule neurons, $\mathrm{MD}$ animals showed a lower percentage of DCXpositive cells ( $p=0.04$, Fig. $2 \mathrm{~F}$ ). This decrease was mainly attributable to cells belonging to categories A-D (Plumpe et al., 2006), representing the more immature phenotype as determined by subsequent morphological characterization (Fig. 2C-E); MD males showed a lower number of the more immature DCX- positive cells type A through $\mathrm{D}(p=0.01)$ (Fig. $2 F$ ) compared with control, while no effect of MD was observed for cells from categories $\mathrm{E}$ and $\mathrm{F}$.

The volumes of the granular cell layer $\left(\mathrm{CON}, 1.14 \pm 0.03 \mathrm{~mm}^{3} ; \mathrm{MD}, 1.07 \pm\right.$ $\left.0.03 \mathrm{~mm}^{3} ; p=0.12\right)$ and molecular cell layer $\left(\mathrm{CON}, 3.38 \pm 0.08 \mathrm{~mm}^{3}\right.$; $\mathrm{MD}$, $\left.3.31 \pm 0.15 \mathrm{~mm}^{3} ; p=0.67\right)$ of the dentate gyrus were not significantly changed by maternal deprivation. Also, total granule cell number was comparable $(\mathrm{CON}$, $769,795 \pm 17,817 ; \mathrm{MD}, 805,349 \pm 33,316$; $p=0.38)$.

\section{Experiment III: dendritic complexity is} altered by maternal deprivation

Maternal deprivation affected the shape of the dendritic tree of granule neurons in adult males (Table 1). Representative examples of reconstructed Golgi-stained neurons are shown in Figure 3, A (CON) and $B(\mathrm{MD})$. Although total dendritic length and the number of branch points were not changed, MD treatment decreased the number of primary dendrites $(p=0.03)$, which was paralleled by an increase in the maximum length of individual primary dendrites $(p=0.04)$. This resulted in a decreased dendritic mass in the proximal part of the dendritic tree (1-85 $\mu \mathrm{m}$ from the soma; repeatedmeasures ANOVA, main effect for treatment, $\left.F_{(1,12)}=7.82 ; p=0.02\right)$, as revealed by Sholl analysis (Fig. $3 C$ ). In addition, there was a trend for an increased total spine density in both the proximal and distal part of the dendritic tree $(p=0.09)$.

\section{Experiment IV: synaptic plasticity in a stressful context is enhanced after}

\section{maternal deprivation}

First, we examined whether LTP could be induced in the dentate gyrus using theta burst stimulation, but in neither CON $(n=12)$ nor MD $(n=9)$ animals was the DG network significantly potentiated. The presence of the stress hormone corticosterone did not change this (repeated-measures ANOVA baseline vs posttheta burst stimulation $\left.(1-60 \mathrm{~min}), F_{(1,29)}=0.03 ; p=0.86\right)$. This is not unprecedented, since GABAergic innervation is known to drive dentate granule cells in vitro away from their firing threshold (Wisden et al., 1992; Coulter and Carlson, 2007). Therefore, we applied theta burst stimulation in the presence of the GABAergic antagonist bicuculline methiodide, which resulted in an overall significant induction of LTP (repeated-measures ANOVA, $\left.F_{(1,30)}=18.75 ; p<0.001\right)$. Therefore, in all experiments described below, bicuculline was present.

There were no differences between $\mathrm{CON}(n=11)$ and $\mathrm{MD}$ $(n=10)$ animals concerning the maximum response (CON, $-2.49 \pm 0.21 \mathrm{mV} ; \mathrm{MD},-2.66 \pm 0.24 \mathrm{mV} ; p=0.60)$, the halfmaximum stimulation intensity $(\mathrm{CON}, 1.91 \pm 0.02$ arbitrary units; MD, $1.92 \pm 0.02$ arbitrary units; $p=0.84$ ), or the half- 

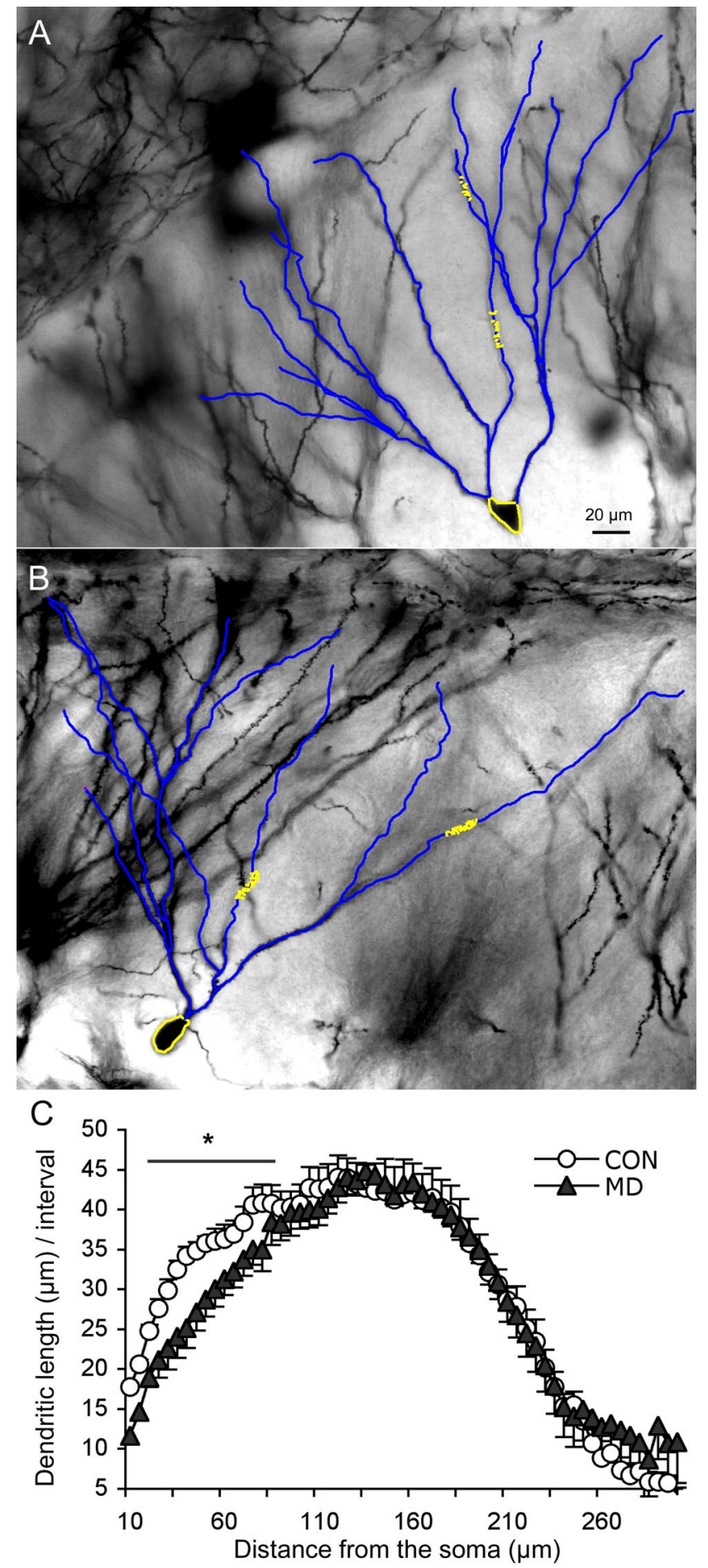

Figure 3. MD alters granule cell morphology in the dentate gyrus $A, B$, Representative example of a Golgi-stained neuron and corresponding dendritic tree of a granule neuron in a control animal $(\boldsymbol{A})$ and a MD animal $(\boldsymbol{B})$. The 3D tracing of dendrites can be seen in blue, and the location of the proximal and distal part of the dendritic tree where spines were quantified is indicated in yellow ( $n=$ 7 animals per group). C, MD animals show a loss of dendritic mass in the proximal part of the dendritic tree (up to $85 \mu \mathrm{m}$ from the soma) as revealed by Sholl analysis $\left({ }^{*} p=0.02\right.$ ).

maximum response $(\mathrm{CON},-1.51 \pm 0.12 \mathrm{mV}$; $\mathrm{MD},-1.49 \pm$ $0.14 \mathrm{mV} ; p=0.93)$, as determined from the input-output curve.

The effects of corticosterone on the degree of long-term potentiation was determined by perfusion of $100 \mathrm{~nm}$ corticosterone during the second half of baseline recordings, coterminating with the end of theta burst stimulation. Corticosterone application in
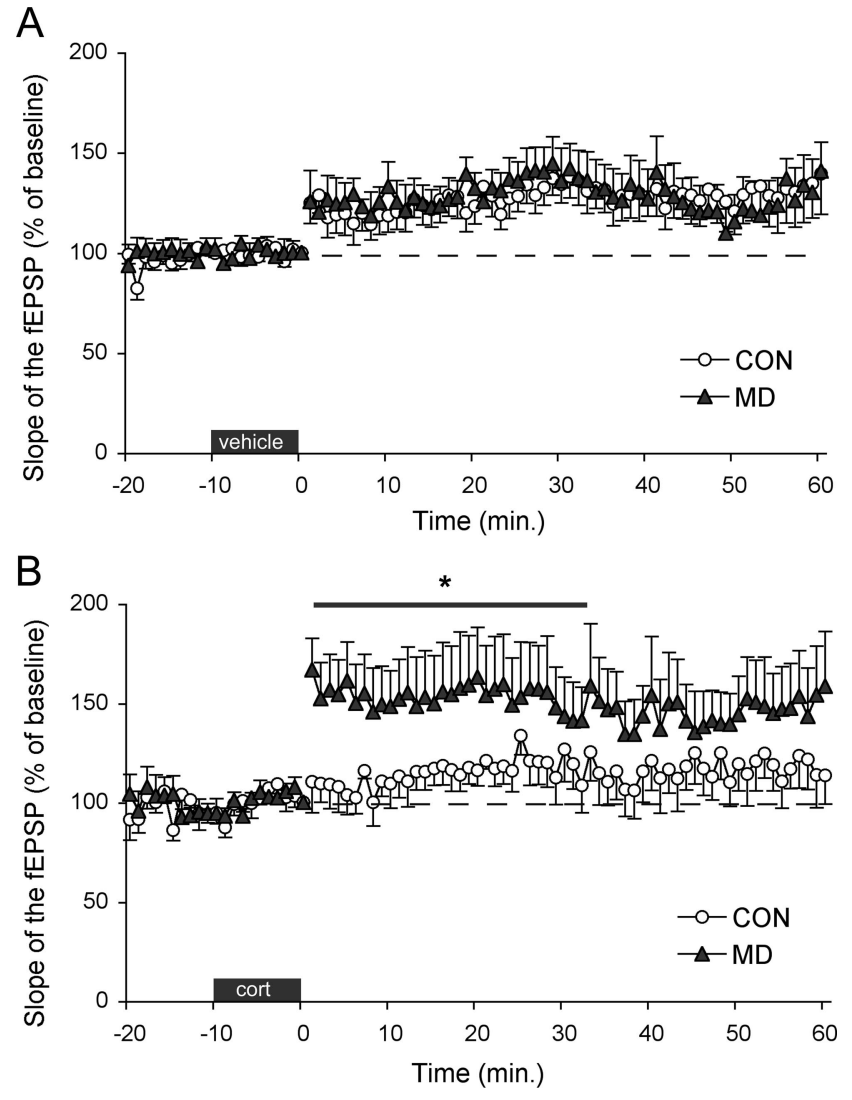

Figure 4. Effects of MD on synaptic plasticity. $A$, LTP measured under vehicle conditions ( $C O N, n=10 ; M D, n=10)$. There was no effect of maternal deprivation on the degree of LTP in the dentate gyrus after theta burst stimulation. $\boldsymbol{B}$, LTP measured after acute CORT application. In the presence of corticosterone, MD animals show a significantly greater LTP compared with CON $\left({ }^{*} p=0.01\right)$. In CON animals $(n=6)$, no significant LTP ( $\left.p=0.67\right)$ was induced. All effects are significant over the first $30 \mathrm{~min}$ after theta burst stimulation.

itself had no effect on the magnitude of the signal during the second half of baseline recordings, as revealed by a three-way repeated-measures ANOVA comparing baseline $1(t=-20$ to $-10 \mathrm{~min}$ ) with baseline $2(t=-10$ to $0 \mathrm{~min})$ (baseline $\times$ drug $X$ group, $F_{(1,30)}=0.03, p=0.86$; drug $\times$ group, $F_{(1,30)}=0.04, p=$ $0.84)$. For LTP, we found a significant main effect of group (CON vs $\left.\mathrm{MD} ; F_{(1,30)}=5.60, p=0.02\right)$ and a significant interaction effect between group (CON vs MD) and treatment (VEH vs CORT; $\left.F_{(1,30)}=4.30, p=0.04\right)$, comparing the second half of baseline recordings with the first $30 \mathrm{~min}$ of after theta burst stimulation recordings. As can be seen from Figure $4 A$, there was no difference in the degree of LTP $(t=0-30 \mathrm{~min})$ between CON $(n=10)$ and $\mathrm{MD}(n=10)$ recordings under VEH conditions (post hoc LSD, $p=0.81$ ). However, as can be seen from Figure $4 B$, application of corticosterone prevented the induction of LTP in recordings from CON animals $(n=6)$ (repeated-measures ANOVA revealed no difference between after and after theta burst stimulation, $\left.F_{(1,6)}=0.22, p=0.67\right)$ and enhanced LTP in recordings from MD animals $(n=8)$ ( post hoc MD VEH vs MD CORT, $p=0.04$ ). This resulted in a significant difference in after theta burst stimulation recordings between $\mathrm{CON}$ and $\mathrm{MD}$ animals in the presence of CORT $(p=0.01)$.

Experiment V: spatial learning is impaired, but emotional memory is improved by maternal deprivation

Baseline anxiety, as determined by elevated plus maze exploration, was not affected by maternal deprivation; there were no 


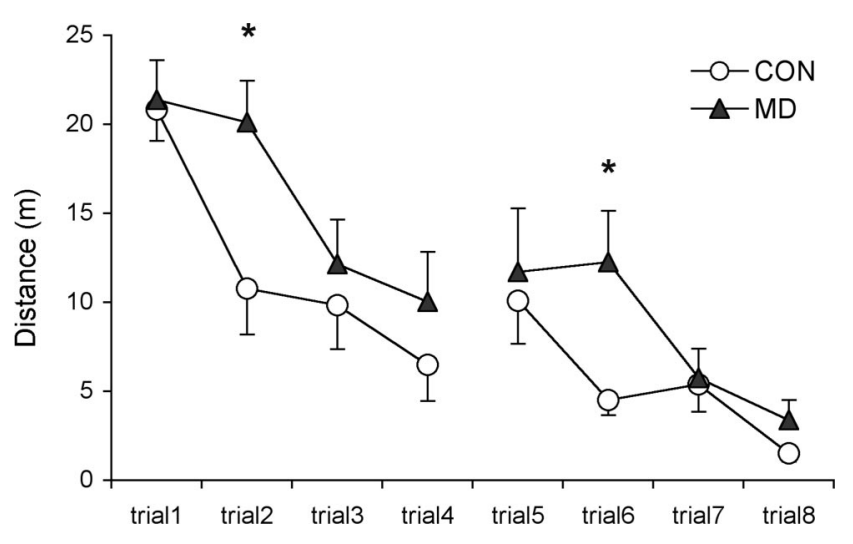

Figure 5. MD impairs Morris water maze learning. MD animals showed an overall impaired spatial acquisition (repeated measures ANOVA, main effect of early life treatment, $p<0.05$ ) and required more travel distance to reach the hidden platform than $\mathrm{CON}$ animals. This effect was most pronounced on the second trial of both training days (trial 2 and trial 6 , both ${ }^{*} p=0.02$ ).

significant differences in latency to first appearance (CON, $51.7 \pm 21.0 \mathrm{~s} ; \mathrm{MD}, 32.2 \pm 10.7 \mathrm{~s} ; p=0.33$ ), visiting frequency (CON, $7.8 \pm 1.5$ times; MD, $7.5 \pm 1.7$ times; $p=0.89$ ), and/or percentage of time spent in the open arms of the maze (CON, $40.1 \pm 6.3 \%$; MD, $45.3 \pm 6.5 \% ; p=0.55$ ).

Spatial acquisition of the water maze test was significantly hampered by maternal deprivation (Fig. 5). MD animals required more time (repeated-measures ANOVA, $F_{(1,18)}=5.83, p=0.03$ ) and travel distance $\left(F_{(1,18)}=4.45 ; p<0.05\right)$ to reach the hidden platform. This difference was most apparent on the second trial of both days $(p=0.02)$. However, both CON and MD animals did acquire the task equally well by the end of the training period ( $p=0.16$ ). Moreover, memory retention after $7 \mathrm{~d}$, as measured by the total time spent in the platform quadrant during the probe trial, was not affected by MD treatment (data not shown, $p=0.47$ ).

To examine emotional memory, animals were trained in a fear-conditioning paradigm using a single mild footshock $(2 \mathrm{~s}$, $0.4 \mathrm{~mA}$ ) that was paired with a tone. During training, freezing behavior was comparable between control and maternally deprived animals both under baseline conditions $(p=0.74)$ and after the tone-footshock combination $(p=0.96)$. Twenty-four hours later, animals were placed in the same context for $3 \mathrm{~min}$. Initially, both groups showed little freezing behavior. However, in $\mathrm{MD}$ animals freezing behavior significantly increased over time, while freezing in control animals remained at a constant rather low level (Fig. $6 \mathrm{~A}$ ) (group $\times$ interval; $F_{(5,125)}=2.3 ; p<$ 0.05 ). This resulted in an increased freezing response in the MD animals versus $\mathrm{CON}$ animals when measured over the last three intervals $(p=0.02)$. In the cued fear conditioning task, MD treatment resulted in a significant increase in freezing behavior in response to the tone ( $p=0.02$, Fig. $6 B)$.

\section{Discussion}

We show that severe early life stress results in lower levels of neurogenesis, changes in granule cell morphology, and impaired spatial learning, yet leads to enhanced synaptic plasticity in vitro in the presence of corticosterone and to improved fear memory formation. Thus, extensive yet differential structural and functional adaptation occurs following maternal deprivation on PND3.
A

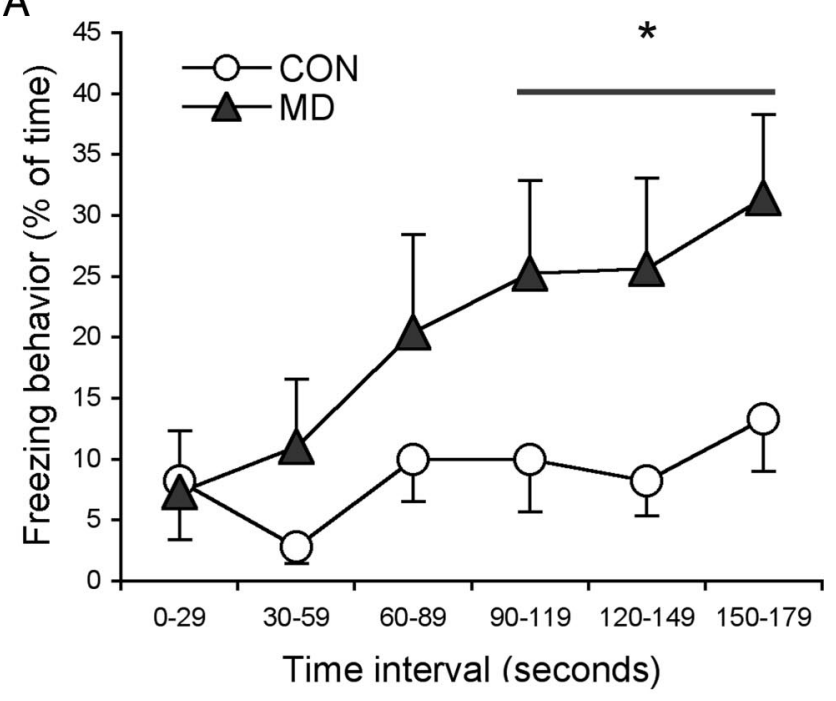

B

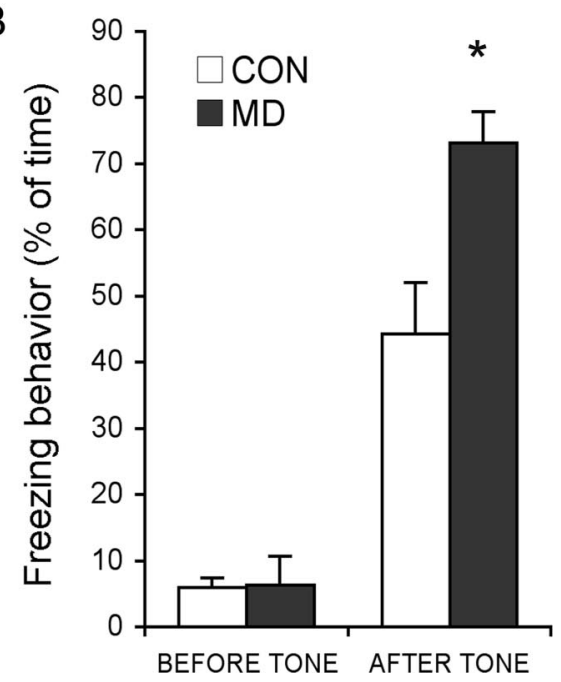

Figure 6. MD enhances contextual and cued fear conditioning. $\boldsymbol{A}$, Maternal deprivation increased freezing behavior in response to the context (repeated-measures ANOVA, treatment $X$ interval interaction, $p<0.05$ ), resulting in an increased level of freezing when analyzed over the last three intervals $\left({ }^{*} p=0.02\right) . \boldsymbol{B}, \mathrm{MD}$ animals show increased freezing behavior in response to the tone when compared with controls $\left({ }^{*} p=0.02\right)$.

\section{Effects of maternal deprivation on adult neurogenesis}

Adult hippocampal neurogenesis is reduced by stress (Cameron and Gould, 1994; Lucassen et al., 2010) and is usually reversible in adulthood (Heine et al., 2004). During early postnatal stress, the rise in corticosterone level coincides with a crucial moment in DG development. We showed previously that this causes an unexpected increased neurogenesis in 3-week-old male rats (Oomen et al., 2009). This increase in prepubertal animals appears to be transient, as 10 -week-old males (this study) show a decrease in neurogenesis.

Postnatal experience can influence adult neurogenesis, and earlier studies using repeated MD have shown an inhibitory effect on cell proliferation (Mirescu et al., 2004; Aisa et al., 2009), whereas handling and high maternal care increase cell survival (Bredy et al., 2003; Lemaire et al., 2006). Since proliferation was reduced by $\mathrm{MD}$, possibly resulting in less BrdU labeling, we cannot state here that survival of newborn cells is reduced. In fact, proliferation was reduced over the entire rostro-to-caudal axis, yet reduced BrdU labeling was observed caudally. This might 
indicate that MD increases newborn cell survival in the rostral hippocampus. The caudal part largely contains the ventral hippocampus or temporal region of the septotemporal axis, which is anatomically and functionally distinct from the rostral part (Maggio and Segal, 2007) and associated with the amygdala (Kjelstrup et al., 2002; Bannerman et al., 2004). Changed neurogenesis after stress and antidepressant treatment are more pronounced in the ventral hippocampus (Banasr et al., 2006; Sahay and Hen, 2007; Paizanis et al., 2009).

\section{Effects of MD on dendritic morphology of granule neurons}

MD altered morphology of granule neurons. Our results did not show overall atrophy, and fewer primary dendrites can be a sign of more immature neurons (Claiborne et al., 1990). However, the data rather points to dendritic reorganization after MD, since decreased dendritic material in the proximal part of the tree was paralleled by longer primary dendrites. This may result from the increase in DCX-positive cells on PND21 (Oomen et al., 2009), and changes are indicative of a reorganized neuroanatomical development of the DG. This fits with observations that early life factors can alter morphology by reducing dendritic complexity of DG, CA1, and CA3 neurons (Brunson et al., 2005; Champagne et al., 2008; Bagot et al., 2009).

The present study is not conclusive about the stress hormones involved in structural reorganization. Glucocorticoids are necessary for normal brain maturation (Meyer, 1983; Weinstock, 2001; Welberg and Seckl, 2001) and dendritic integrity depends on continuous mineralocorticoid receptor activation (Wossink et al., 2001), but glucocorticoid overexposure during development can delay CNS maturation (Huang et al., 2001; Alfarez et al., 2009; Lucassen et al., 2009). Differences in postnatal corticosteroid levels, as described after MD (Oomen et al., 2009), may therefore contribute to the morphological alterations in adulthood. However, altered corticotropin-releasing hormone levels early in life could also play a role, as this hormone too is involved in the effects of early life stress on dendritic morphology, particularly in CA3 cells (Brunson et al., 2005). Putative MD-induced shifts in corticosteroid level during adulthood seem less likely; we found no changes in basal corticosteroid levels after MD, and stress-induced corticosteroid levels even tended to be lower after $\mathrm{MD}$, consistent with earlier findings showing age-dependent regulation of HPA axis reactivity by MD (Workel et al., 2001).

\section{Effects of maternal deprivation on synaptic plasticity in the dentate gyrus}

Low excitability of DG granule neurons in vitro is due to strong GABAergic inhibition and a hyperpolarized resting membrane potential (Wisden et al., 1992; Coulter and Carlson, 2007), making it difficult to induce LTP (Pu et al., 2007). Here, significant potentiation only occurred in the presence of the GABAergic antagonist bicuculline.

Early life adversity can impair LTP in CA3 (Brunson et al., 2005), DG (Bagot et al., 2009), and CA1 (Champagne et al., 2008), and MD causes an impairment of stress-induced latephase LTP reinforcement in the DG (Gruss et al., 2008). Here, we found no evidence for reduced DG LTP due to MD treatment alone. Apparently, reduced neurogenesis and altered dendritic complexity do not necessarily affect the ability to elicit synaptic plasticity. Adult-born young neurons facilitate the induction of LTP (Schmidt-Hieber et al., 2004), but differences in neurogenesis may have been obscured by the presence of bicuculline, since newborn neurons lack inhibitory GABAergic input (Wang et al., 2000). Moreover, LTP recordings were performed in the dorsal hippocampus, while MD effects on neurogenesis were most pronounced caudally.

Importantly, the presence of corticosterone during theta burst stimulation enhanced LTP in MD but not control animals. Thus, severe early life stress (24 h MD, PND3) replicates the synaptic plasticity phenotype seen earlier only in the DG of animals that received low amounts of maternal care (Bagot et al., 2009).

The biochemical basis for the effect of MD on hippocampal plasticity is presently unresolved. Brain-derived neurotrophic factor (BDNF) might be involved, as it affects hippocampal structure and plasticity (Cowansage et al., 2009) and is differently expressed in at least some models of early life stress (Kikusui et al., 2009). However, for the present model, it was shown before that $24 \mathrm{~h} \mathrm{MD}$ at PND3 did not alter BDNF expression in the adult hippocampus (Schaaf et al., 2001).

\section{Effects of maternal deprivation on learning and memory}

We found that MD animals poorly acquire the hippocampusdependent water maze. Previously, MD was found to impair water maze performance in adulthood (Oitzl et al., 2000; Uysal et al., 2005; Aisa et al., 2007; Garner et al., 2007). Many studies have found evidence for the involvement of neurogenesis in spatial acquisition (Gould et al., 1999; Clelland et al., 2009), and this type of learning seems mostly dependent on the dorsal hippocampus (Bannerman et al., 1999). A recent study, however, suggests that adult-born neurons in the ventral hippocampus are specifically activated in water maze learning (Snyder et al., 2009). Considering the overall decrease in proliferation, in combination with the effects on neurogenesis in the caudal part of the hippocampus, a reduced neurogenesis and changed neuronal morphology may have contributed to the cognitive impairment observed here.

MD animals showed enhanced contextual and cued fear conditioning. Basal anxiety as measured in the elevated plus maze and during fear training was unaffected. Studies using MD (although paradigms differ from the present study) report either no effect on contextual or cued fear conditioning (Stevenson et al., 2009) or a decreased performance (Lehmann et al., 1999; Kosten et al., 2006; Guijarro et al., 2007). However, Champagne et al. (2008), using a similar fear conditioning protocol, showed that animals with a history of low maternal care have a better memory of the fearful context. Possibly, amygdalar influences on DG network activity (Akirav and Richter-Levin, 1999; Kim and Diamond, 2002; Korz and Frey, 2005) are lastingly affected by early environment, amplified by differences in corticosterone responsiveness in the DG itself as found in our in vitro studies. In addition, differences in corticosterone responsiveness due to early experience in other subregions such as the CA1 can also be expected (Champagne et al., 2008). Moreover, changes in the DG, in view of its function as a filter for incoming information into the hippocampus (Hsu, 2007), may result in altered processing of relevant (stress-related) information downstream of the DG. Therefore, effects of early experience may involve functional changes in hippocampal regions other than the DG. Nevertheless, our observations at the DG cell and circuit level matched quite well with the behavioral observations, underlining that lasting consequences of early experience for DG structure and function are important for hippocampusdependent behavioral output.

Mechanisms underlying differences in fear conditioning and the possible role for corticosterone remain to be determined. Changes in neurogenesis may explain the results on contextual 
fear but not cue learning (Pham et al., 2005; Saxe et al., 2006; Kitamura et al., 2009; Revest et al., 2009). In fear conditioning, as in the water maze, better performance is associated with higher corticosterone levels (Cordero et al., 1998), although a ceiling effect exists (Pugh et al., 1997). Improved learning performance may therefore occur secondary to increased corticosteroid levels in response to stress. While this might be the case for low licking and grooming offspring, which are known to have higher stress-induced corticosterone levels (Liu et al., 1997), it certainly cannot explain the current observations, since MD animals, if anything, showed lower stress-induced corticosterone levels. Rather than differences in hormone level, altered responsiveness to corticosterone may explain why MD rats show stronger contextual fear conditioning and DG LTP in the presence of corticosterone. However, a role of stress hormones other than corticosterone cannot be excluded. Moreover, possible changes in (amygdala) dendritic complexity could play a role in enhanced fear memory.

The present morphological, electrophysiological, and behavioral observations demonstrate that even a severely adverse early life event in rats does not impair overall hippocampal functionality in adulthood. Rather, severe stress in early life might prepare animals to respond optimally under conditions associated with high corticosteroid levels during adulthood, i.e., when the adult and early life conditions closely match. Ultimately, interaction between the individual (epi)genetic profile and the early environment, such as MD, may amplify individual responsiveness in animals and can be involved in adaptive programming.

\section{References}

Aisa B, Tordera R, Lasheras B, Del Rio J, Ramirez MJ (2007) Cognitive impairment associated to HPA axis hyperactivity after maternal separation in rats. Psychoneuroendocrinology 32:256-266.

Aisa B, Elizalde N, Tordera R, Lasheras B, Del Rio J, Ramirez MJ (2009) Effects of neonatal stress on markers of synaptic plasticity in the hippocampus: implications for spatial memory. Hippocampus 19:1222-1231.

Akirav I, Richter-Levin G (1999) Biphasic modulation of hippocampal plasticity by behavioral stress and basolateral amygdala stimulation in the rat. J Neurosci 19:10530-10535.

Alfarez DN, De Simoni A, Velzing EH, Bracey E, Joels M, Edwards FA, Krugers HJ (2009) Corticosterone reduces dendritic complexity in developing hippocampal CA1 neurons. Hippocampus 19:828-836.

Altman J, Bayer SA (1990a) Mosaic organization of the hippocampal neuroepithelium and the multiple germinal sources of dentate granule cells. J Comp Neurol 301:325-342.

Altman J, Bayer SA (1990b) Migration and distribution of two populations of hippocampal granule cell precursors during the perinatal and postnatal periods. J Comp Neurol 301:365-381.

Bagot RC, van Hasselt FN, Champagne DL, Meaney MJ, Krugers HJ, Joels M (2009) Maternal care determines rapid effects of stress mediators on synaptic plasticity in adult rat hippocampal dentate gyrus. Neurobiol Learn Mem 92:292-300.

Banasr M, Soumier A, Hery M, Mocaer E, Daszuta A (2006) Agomelatine, a new antidepressant, induces regional changes in hippocampal neurogenesis. Biol Psychiatry 59:1087-1096.

Bannerman DM, Yee BK, Good MA, Heupel MJ, Iversen SD, Rawlins JN (1999) Double dissociation of function within the hippocampus: a comparison of dorsal, ventral, and complete hippocampal cytotoxic lesions. Behav Neurosci 113:1170-1188.

Bannerman DM, Rawlins JN, McHugh SB, Deacon RM, Yee BK, Bast T, Zhang WN, Pothuizen HH, Feldon J (2004) Regional dissociations within the hippocampus-memory and anxiety. Neurosci Biobehav Rev 28:273-283.

Boekhoorn K, Terwel D, Biemans B, Borghgraef P, Wiegert O, Ramakers GJ, de Vos K, Krugers H, Tomiyama T, Mori H, Joels M, van Leuven F, Lucassen PJ (2006) Improved long-term potentiation and memory in young tau-P301L transgenic mice before onset of hyperphosphorylation and tauopathy. J Neurosci 26:3514-3523.

Bredy TW, Grant RJ, Champagne DL, Meaney MJ (2003) Maternal care influences neuronal survival in the hippocampus of the rat. Eur J Neurosci 18:2903-2909.

Brunson KL, Kramar E, Lin B, Chen Y, Colgin LL, Yanagihara TK, Lynch G, Baram TZ (2005) Mechanisms of late-onset cognitive decline after early-life stress. J Neurosci 25:9328-9338.

Cameron HA, Gould E (1994) Adult neurogenesis is regulated by adrenal steroids in the dentate gyrus. Neuroscience 61:203-209.

Champagne DL, Bagot RC, van Hasselt F, Ramakers G, Meaney MJ, de Kloet ER, Joels M, Krugers H (2008) Maternal care and hippocampal plasticity: evidence for experience-dependent structural plasticity, altered synaptic functioning, and differential responsiveness to glucocorticoids and stress. J Neurosci 28:6037-6045.

Champagne DL, de Kloet ER, Joels M (2009) Fundamental aspects of the impact of glucocorticoids on the (immature) brain. Semin Fetal Neonatal Med 14:136-142.

Claiborne BJ, Amaral DG, Cowan WM (1990) Quantitative, threedimensional analysis of granule cell dendrites in the rat dentate gyrus. J Comp Neurol 302:206-219.

Clelland CD, Choi M, Romberg C, Clemenson GD Jr, Fragniere A, Tyers P, Jessberger S, Saksida LM, Barker RA, Gage FH, Bussey TJ (2009) A functional role for adult hippocampal neurogenesis in spatial pattern separation. Science 325:210-213.

Cordero MI, Merino JJ, Sandi C (1998) Correlational relationship between shock intensity and corticosterone secretion on the establishment and subsequent expression of contextual fear conditioning. Behav Neurosci 112:885-891.

Coulter DA, Carlson GC (2007) Functional regulation of the dentate gyrus by GABA-mediated inhibition. Prog Brain Res 163:235-243.

Cowansage KK, Ledoux JE, Monfils MH (2009) Brain-derived neurotrophic factor: a dynamic gatekeeper of neural plasticity. Curr Mol Pharmacol 3:12-29.

de Kloet ER, Joels M, Holsboer F (2005) Stress and the brain: from adaptation to disease. Nat Rev Neurosci 6:463-475.

Fabricius K, Wortwein G, Pakkenberg B (2008) The impact of maternal separation on adult mouse behaviour and on the total neuron number in the mouse hippocampus. Brain Struct Funct 212:403-416.

Fluttert M, Dalm S, Oitzl MS (2000) A refined method for sequential blood sampling by tail incision in rats. Lab Anim 34:372-378.

Garner B, Wood SJ, Pantelis C, van den Buuse M (2007) Early maternal deprivation reduces prepulse inhibition and impairs spatial learning ability in adulthood: no further effect of post-pubertal chronic corticosterone treatment. Behav Brain Res 176:323-332.

Gould E, Beylin A, Tanapat P, Reeves A, Shors TJ (1999) Learning enhances adult neurogenesis in the hippocampal formation. Nat Neurosci 2:260-265.

Greisen MH, Altar CA, Bolwig TG, Whitehead R, Wortwein G (2005) Increased adult hippocampal brain-derived neurotrophic factor and normal levels of neurogenesis in maternal separation rats. J Neurosci Res 79:772-778.

Gruss M, Braun K, Frey JU, Korz V (2008) Maternal separation during a specific postnatal time window prevents reinforcement of hippocampal long-term potentiation in adolescent rats. Neuroscience 152:1-7.

Guijarro JZ, Tiba PA, Ferreira TL, Kawakami SE, Oliveira MG, Suchecki D (2007) Effects of brief and long maternal separations on the HPA axis activity and the performance of rats on context and tone fear conditioning. Behav Brain Res 184:101-108.

Heim C, Nemeroff CB (2001) The role of childhood trauma in the neurobiology of mood and anxiety disorders: preclinical and clinical studies. Biol Psychiatry 49:1023-1039.

Heine VM, Maslam S, Zareno J, Joels M, Lucassen PJ (2004) Suppressed proliferation and apoptotic changes in the rat dentate gyrus after acute and chronic stress are reversible. Eur J Neurosci 19:131-144.

Hsu D (2007) The dentate gyrus as a filter or gate: a look back and a look ahead. Prog Brain Res 163:601-613.

Huang WL, Harper CG, Evans SF, Newnham JP, Dunlop SA (2001) Repeated prenatal corticosteroid administration delays myelination of the corpus callosum in fetal sheep. Int J Dev Neurosci 19:415-425.

Huot RL, Plotsky PM, Lenox RH, McNamara RK (2002) Neonatal maternal 
separation reduces hippocampal mossy fiber density in adult Long Evans rats. Brain Res 950:52-63.

Karst H, Karten YJ, Reichardt HM, de Kloet ER, Schutz G, Joels M (2000) Corticosteroid actions in hippocampus require DNA binding of glucocorticoid receptor homodimers. Nat Neurosci 3:977-978.

Kikusui T, Ichikawa S, Mori Y (2009) Maternal deprivation by early weaning increases corticosterone and decreases hippocampal BDNF and neurogenesis in mice. Psychoneuroendocrinology 34:762-772.

Kim JJ, Diamond DM (2002) The stressed hippocampus, synaptic plasticity and lost memories. Nat Rev Neurosci 3:453-462.

Kitamura T, Saitoh Y, Takashima N, Murayama A, Niibori Y, Ageta H, Sekiguchi M, Sugiyama H, Inokuchi K (2009) Adult neurogenesis modulates the hippocampus-dependent period of associative fear memory. Cell 139:814-827.

Kjelstrup KG, Tuvnes FA, Steffenach HA, Murison R, Moser EI, Moser MB (2002) Reduced fear expression after lesions of the ventral hippocampus. Proc Natl Acad Sci U S A 99:10825-10830.

Korz V, Frey JU (2005) Bidirectional modulation of hippocampal longterm potentiation under stress and no-stress conditions in basolateral amygdala-lesioned and intact rats. J Neurosci 25:7393-7400.

Kosten TA, Lee HJ, Kim JJ (2006) Early life stress impairs fear conditioning in adult male and female rats. Brain Res 1087:142-150.

Kronenberg G, Reuter K, Steiner B, Brandt MD, Jessberger S, Yamaguchi M, Kempermann G (2003) Subpopulations of proliferating cells of the adult hippocampus respond differently to physiologic neurogenic stimuli. J Comp Neurol 467:455-463.

Lehmann J, Pryce CR, Bettschen D, Feldon J (1999) The maternal separation paradigm and adult emotionality and cognition in male and female Wistar rats. Pharmacol Biochem Behav 64:705-715.

Lehmann J, Russig H, Feldon J, Pryce CR (2002) Effect of a single maternal separation at different pup ages on the corticosterone stress response in adult and aged rats. Pharmacol Biochem Behav 73:141-145.

Lemaire V, Lamarque S, Le Moal M, Piazza PV, Abrous DN (2006) Postnatal stimulation of the pups counteracts prenatal stress-induced deficits in hippocampal neurogenesis. Biol Psychiatry 59:786-792.

Leventopoulos M, Ruedi-Bettschen D, Knuesel I, Feldon J, Pryce CR, Opacka-Juffry J (2007) Long-term effects of early life deprivation on brain glia in Fischer rats. Brain Res 1142:119-126.

Levine S, Huchton DM, Wiener SG, Rosenfeld P (1991) Time course of the effect of maternal deprivation on the hypothalamic-pituitary-adrenal axis in the infant rat. Dev Psychobiol 24:547-558.

Liu D, Diorio J, Tannenbaum B, Caldji C, Francis D, Freedman A, Sharma S, Pearson D, Plotsky PM, Meaney MJ (1997) Maternal care, hippocampal glucocorticoid receptors, and hypothalamic-pituitary-adrenal responses to stress. Science 277:1659-1662.

Liu D, Diorio J, Day JC, Francis DD, Meaney MJ (2000) Maternal care, hippocampal synaptogenesis and cognitive development in rats. Nat Neurosci 3:799-806.

Lucassen PJ, Bosch O, Jousma E, Krömer SA, Andrews R, Seckl JR, Neumann ID (2009) Prenatal stress reduces postnatal neurogenesis in rats selectively bred for high, but not low anxiety: possible key role of lack of induction of placental 11B-hydroxysteroid dehydrogenase type 2. Eur J Neurosci 29: 97-103.

Lucassen PJ, Meerlo P, Naylor AS, van Dam AM, Dayer AG, Fuchs E, Oomen CA, Czeh B (2010) Regulation of adult neurogenesis by stress, sleep disruption, exercise and inflammation: implications for depression and antidepressant action. Eur Neuropsychopharmacol 20:1-17.

Lyons DM, Parker KJ, Katz M, Schatzberg AF (2009) Developmental cascades linking stress inoculation, arousal regulation, and resilience. Front Behav Neurosci 3:32.

Maggio N, Segal M (2007) Striking variations in corticosteroid modulation of long-term potentiation along the septotemporal axis of the hippocampus. J Neurosci 27:5757-5765.

Mayer JL, Klumpers L, Maslam S, de Kloet ER, Joels M, Lucassen PJ (2006) Brief treatment with the glucocorticoid receptor antagonist mifepristone normalises the corticosterone-induced reduction of adult hippocampal neurogenesis. J Neuroendocrinol 18:629-631.

McEwen BS (2003) Early life influences on life-long patterns of behavior and health. Ment Retard Dev Disabil Res Rev 9:149-154.

McEwen BS, Magarinos AM (2001) Stress and hippocampal plasticity: implications for the pathophysiology of affective disorders. Hum Psychopharmacol 16:S7-S19.
Meyer JS (1983) Early adrenalectomy stimulates subsequent growth and development of the rat brain. Exp Neurol 82:432-446.

Mirescu C, Peters JD, Gould E (2004) Early life experience alters response of adult neurogenesis to stress. Nat Neurosci 7:841-846.

Morris R (1984) Developments of a water-maze procedure for studying spatial learning in the rat. J Neurosci Methods 11:47-60.

Oitzl MS, Workel JO, Fluttert M, Frosch F, De Kloet ER (2000) Maternal deprivation affects behaviour from youth to senescence: amplification of individual differences in spatial learning and memory in senescent Brown Norway rats. Eur J Neurosci 12:3771-3780.

Oomen CA, Mayer JL, de Kloet ER, Joels M, Lucassen PJ (2007) Brief treatment with the glucocorticoid receptor antagonist mifepristone normalizes the reduction in neurogenesis after chronic stress. Eur J Neurosci 26:3395-3401.

Oomen CA, Girardi CE, Cahyadi R, Verbeek EC, Krugers H, Joels M, Lucassen PJ (2009) Opposite effects of early maternal deprivation on neurogenesis in male versus female rats. PLoS One 4:e3675.

Paizanis E, Renoir T, Lelievre V, Saurini F, Melfort M, Gabriel C, Barden N, Mocaer E, Hamon M, Lanfumey L (2009) Behavioural and neuroplastic effects of the new-generation antidepressant agomelatine compared to fluoxetine in glucocorticoid receptor-impaired mice. Int J Neuropsychopharmacol 24:1-16.

Paxinos G, Watson C (1986) The rat brain in stereotaxic coordinates, Ed 2. San Diego: Academic.

Penke Z, Felszeghy K, Fernette B, Sage D, Nyakas C, Burlet A (2001) Postnatal maternal deprivation produces long-lasting modifications of the stress response, feeding and stress-related behaviour in the rat. Eur J Neurosci 14:747-755.

Petersen A, Wortwein G, Gruber SH, Mathe AA (2008) Escitalopram reduces increased hippocampal cytogenesis in a genetic rat depression model. Neurosci Lett 436:305-308.

Pham K, McEwen BS, Ledoux JE, Nader K (2005) Fear learning transiently impairs hippocampal cell proliferation. Neuroscience 130:17-24.

Phillips RG, LeDoux JE (1992) Differential contribution of amygdala and hippocampus to cued and contextual fear conditioning. Behav Neurosci 106:274-285.

Plotsky PM, Meaney MJ (1993) Early, postnatal experience alters hypothalamic corticotropin-releasing factor (CRF) mRNA, median eminence $\mathrm{CRF}$ content and stress-induced release in adult rats. Brain Res Mol Brain Res 18:195-200.

Plumpe T, Ehninger D, Steiner B, Klempin F, Jessberger S, Brandt M, Romer B, Rodriguez GR, Kronenberg G, Kempermann G (2006) Variability of doublecortin-associated dendrite maturation in adult hippocampal neurogenesis is independent of the regulation of precursor cell proliferation. BMC Neurosci 7:77.

Pu Z, Krugers HJ, Joels M (2007) Corticosterone time-dependently modulates beta-adrenergic effects on long-term potentiation in the hippocampal dentate gyrus. Learn Mem 14:359-367.

Pugh CR, Tremblay D, Fleshner M, Rudy JW (1997) A selective role for corticosterone in contextual-fear conditioning. Behav Neurosci 111:503-511.

Revest JM, Dupret D, Koehl M, Funk-Reiter C, Grosjean N, Piazza PV, Abrous DN (2009) Adult hippocampal neurogenesis is involved in anxiety-related behaviors. Mol Psychiatry 14:959-967.

Sahay A, Hen R (2007) Adult hippocampal neurogenesis in depression. Nat Neurosci 10:1110-1115.

Saxe MD, Battaglia F, Wang JW, Malleret G, David DJ, Monckton JE, Garcia AD, Sofroniew MV, Kandel ER, Santarelli L, Hen R, Drew MR (2006) Ablation of hippocampal neurogenesis impairs contextual fear conditioning and synaptic plasticity in the dentate gyrus. Proc Natl Acad Sci U S A 103:17501-17506.

Schaaf MJ, Workel JO, Lesscher HM, Vreugdenhil E, Oitzl MS, de Kloet ER (2001) Correlation between hippocampal BDNF mRNA expression and memory performance in senescent rats. Brain Res 915:227-233.

Schmidt M, Enthoven L, van Woezik JH, Levine S, de Kloet ER, Oitzl MS (2004) The dynamics of the hypothalamic-pituitary-adrenal axis during maternal deprivation. J Neuroendocrinol 16:52-57.

Schmidt-Hieber C, Jonas P, Bischofberger J (2004) Enhanced synaptic plasticity in newly generated granule cells of the adult hippocampus. Nature 429:184-187.

Snyder JS, Radik R, Wojtowicz JM, Cameron HA (2009) Anatomical gradients of adult neurogenesis and activity: young neurons in the ventral 
dentate gyrus are activated by water maze training. Hippocampus 19:360-370.

Stevenson CW, Spicer CH, Mason R, Marsden CA (2009) Early life programming of fear conditioning and extinction in adult male rats. Behav Brain Res 205:505-510.

Uysal N, Ozdemir D, Dayi A, Yalaz G, Baltaci AK, Bediz CS (2005) Effects of maternal deprivation on melatonin production and cognition in adolescent male and female rats. Neuro Endocrinol Lett 26:555-560.

van Praag H, Kempermann G, Gage FH (1999) Running increases cell proliferation and neurogenesis in the adult mouse dentate gyrus. Nat Neurosci 2:266-270.

Walker TL, Yasuda T, Adams DJ, Bartlett PF (2007) The doublecortin expressing population in the developing and adult brain contains multipotential precursors in addition to neuronal-lineage cells. J Neurosci 27: 3734-3742.

Wang S, Scott BW, Wojtowicz JM (2000) Heterogenous properties of dentate granule neurons in the adult rat. J Neurobiol 42:248-257.

Wearne SL, Rodriguez A, Ehlenberger DB, Rocher AB, Henderson SC, Hof PR (2005) New techniques for imaging, digitization and analysis of three-dimensional neural morphology on multiple scales. Neuroscience 136:661-680.

Weinstock M (2001) Alterations induced by gestational stress in brain morphology and behaviour of the offspring. Prog Neurobiol 65:427-451.

Welberg LA, Seckl JR (2001) Prenatal stress, glucocorticoids and the programming of the brain. J Neuroendocrinol 13:113-128.

Wisden W, Laurie DJ, Monyer H, Seeburg PH (1992) The distribution of 13 $\mathrm{GABA}_{\mathrm{A}}$ receptor subunit mRNAs in the rat brain. I. Telencephalon, diencephalon, mesencephalon. J Neurosci 12:1040-1062.

Workel JO, Oitzl MS, Fluttert M, Lesscher H, Karssen A, de Kloet ER (2001) Differential and age-dependent effects of maternal deprivation on the hypothalamic-pituitary-adrenal axis of Brown Norway rats from youth to senescence. J Neuroendocrinol 13:569-580.

Wossink J, Karst H, Mayboroda O, Joels M (2001) Morphological and functional properties of rat dentate granule cells after adrenalectomy. Neuroscience 108:263-272.

Zhou M, Conboy L, Sandi C, Joels M, Krugers HJ (2009) Fear conditioning enhances spontaneous AMPA receptor-mediated synaptic transmission in mouse hippocampal CA1 area. Eur J Neurosci 30:1559-1564. 